\title{
Fault Reason and Diagnosis of Electronic Control Automatic Transmission of Modern
}

\author{
Kun Liu, Xiping Song, Xiangyu Li \\ University of Vehicle Engineering, Jingmen Technology, Hubei, China
}

\begin{abstract}
The mechanical transmission of automobile is very efficient, reliable and structurally simple, but is easy to wear the parts prematurely because of its dynamic load. In the case of complex external conditions, the frequent operation of the clutch, shift lever and throttle, increasing the burden on the driver is not conducive to safe driving. In recent decades, automatic transmission has been an unprecedented development; electronic control automatic transmission has become the development direction of modern car transmission. But the electronic control automatic transmission structure complex production cost is high; its repair and troubleshooting put forward the harsh requirements of the maintenance personnel, maintenance technology. Understanding the degree also constitutes a certain degree of difficulty. The modern car electronic control automatic transmission development history, composition and function of the failure of the file are not up to speed to make a major study. The cause and diagnosis of the exclusion of the automatic control of automotive electronic control and maintenance are of great significance.
\end{abstract}

Keywords: electronic control automatic transmission upshift not speed detection maintenance failure causes

Received: $18^{\text {th }}$ Jan. $2019 \quad$ Accepted: $6^{\text {th }}$ Apr. 2019 Online: $20^{\text {th }}$ Apr. 2019

\section{Introduction}

The automatic transmission with hydraulic torque converter shows more excellent performance than the automatic gearbox with the coupler: the starting torque is large and the acceleration performance is good and the impact of the driveline is reduced. However, their working principle and maintenance is more complex, which requires maintenance technicians to understand the principle of automatic transmission and maintenance, in order to better use the automatic transmission and maintenance. In this paper, the implementation of electronic control automatic transmission and electronic control and its sensor to make its main research, focusing on the electronic control of automatic transmission upshift failure analysis and the reasons for failure and the exclusion of the precautions made more comprehensive exposition.

Electronic control automatic transmission due to the complexity of its operation method requirements such as the operation is not standardized caused by serious damage to the transmission, and now most of the owners of the operation method is not standardized damage to the automatic transmission, and the general repair shop cannot repair the electronic Control automatic transmission, electronic control automatic transmission repair process is more complex, and different cars of the automatic transmission structure is very different, for the cause of failure and diagnosis of the method and operation of the proposed process demanding.

\section{The electronic control automatic transmission overview}

\subsection{Automotive electronic control automatically to the development of a brief history}

A Brief Introduction to the Development of Automotive Electronic Control Automatic Transmission

Automatic gearbox development so far, has been 60 years of history. From 1939 the United States General Motor developed hydraulic couplings and planetary gears composed of four-speed hydraulic gearbox began. Due to the various advantages of hydraulic transmission, attracting the world's major automobile manufacturers is actively involved in the development and development of automatic transmission. Until 1950, the United States Ford successfully developed the

Copyright (C) 2019 Kun Liu et al. This is an Open Access article distributed under the terms of the Creative Commons Attribution - NonCommercial 4.0 International License (http://creativecommons.org/licenses/by-nc/4.0/), permitting all non-commercial use, distribution, and reproduction in any medium, provided the original work is properly cited. 
three-component hydraulic transmission structure of the three-speed automatic transmission, automatic transmission from the beginning to mature.

The automatic transmission with hydraulic torque converter shows more excellent performance than the automatic gearbox with coupler: high starting torque, good acceleration performance, reduced impact of the drive train, torque on engine crankshaft Vibration and the role of isolation, etc., due to low transmission efficiency reasons, Ford has adopted a lock-up clutch mechanism, thus to overcome this problem. Thus, completing the complete conversion from the original automatic transmission to the modern automatic transmission.

The mid-80s of the 20th century, Japan's largest car manufacturer Toyota successfully developed a super-speed metrically controlled hydraulic automatic transmission. The emergence of this creation, but also for the development of automatic transmission to a new stage. By the late 1990s, the three major US auto companies have launched their own electronic control hydraulic automatic transmission, from the development of automatic transmission began to enter the electronic control stage, hydraulic automatic transmission was gradually eliminated.

With the development of computers, electronic control automatic transmission in the electronic control technology gradually matures. Some of the high-end technology has gradually been applied to the automation control, such as: fuzzy control theory, Bluetooth technology, CAN bus and so on. For example, Volkswagen's 01N, 01M and 01V models use these technologies to varying degrees. Citroen's AL4 automatic transmission, to achieve a fully automatic control, P, R, N, $\mathrm{D}$ and reverse position are used solenoid valve control, and set the maximum number of automatic transmission solenoid valve records. This mark from the beginning of the 21 st century, automatic transmission in the reliability, the smoothness of the shift and other aspects have been greatly improved to meet the people on the car design concept of human requirements.

\subsection{Automotive electronic control automatic transmission type and composition and function}

Electronic control automatic transmission type

(1) Transmission classification based on ratio

According to the transmission ratio of the way, automatic transmission is divided into hierarchical, step less and integrated types.

(1) Level automatic transmission.

It refers to automatic mechanical transmission (AMT), which is based on the mechanical gear transmission, which has three main parts: automatic clutch, gear type mechanical transmission and electronic control system.

(2) Step less automatic transmission.

It is the realization of continuous transmission without transmission (Continuously Variable Transmission, referred to as CVT), commonly used metal belt continuously variable transmission, with a continuous transmission ratio, transmission power smooth and easy to operate through the thin steel sheet into the strip is twisted on the different radii of the two cone wheels to change the speed ratio.

(3) Integrated automatic transmission

It refers to the automatic control of the hydraulic mechanical automatic transmission (automatic transmission, referred to as AT), the basic form of the torque converter and planetary gears in series for the characteristics of a compact, smooth transmission, the impact of small shift Features.

(2) Classification based on control

According to different control methods, automatic transmission can be divided into hydraulic control and electronic control automatic transmission.

(1) Hydraulic control automatic transmission

Hydraulic control automatic transmission is through the mechanical means, the car driving speed and throttle position of the two parameters into the hydraulic control signal, the valve plate in the various control valves according to the size of these hydraulic signals, according to the set Shift law, by controlling the operation of the shift components to achieve automatic shift. As shown in Figure 1. 
(2) Electronic control automatic transmission

Electronic control automatic transmission equipped with a computer, through a variety of sensors, the engine speed, throttle opening, speed, engine water temperature, automatic transmission oil temperature and other parameters into electrical signals, and enter the computer, the computer according to these signals, according to set The shift of the electromagnetic valve, hydraulic solenoid valve, etc. issued electronic control signal, shift solenoid valve, hydraulic solenoid valve and then the computer's electronic control signal into a hydraulic control signal, the valve plate in the various control valves According to these hydraulic control signals, control the operation of the shift actuator, in order to achieve automatic shift, as shown in Figure 2.

Figure 1. Hydraulic automatic transmission control process diagram
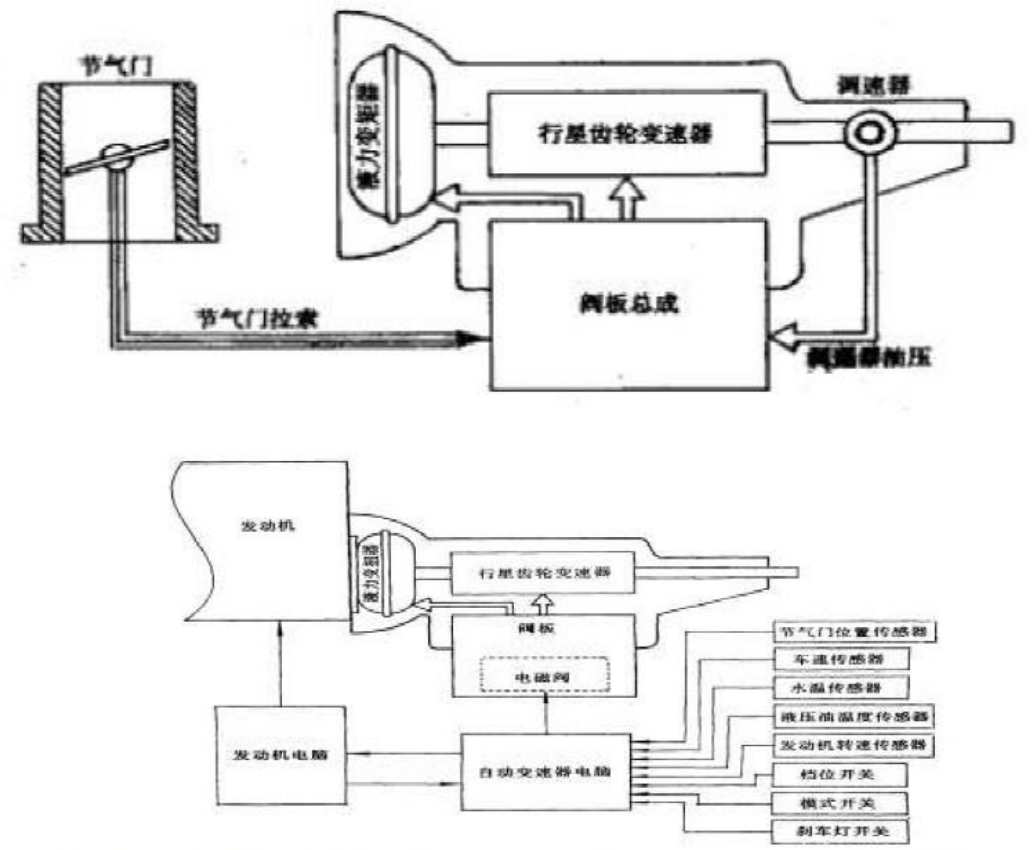

Figure 2. Schematic diagram of the control process of the electronic control automatic transmission

\subsection{Electronic control automatic transmission composition and function}

(1) Hydraulic torque converter: The torque converter is located at the forefront of the automatic transmission, which is connected to the flywheel of the engine by bolts, which is similar to the clutch in a car with a manual transmission. It uses the principle of hydraulic transmission, the engine power transmission to the automatic transmission of the input shaft, is a soft connection.

(2) Gear transmission: gear transmission is the main component of the automatic transmission, the transmission can achieve different transmission ratio, so that in different stalls, generally have 3 to 4 forward and 1 reverse. With the hydraulic torque converter, you can get from the start to the highest speed within the entire range of automatic transmission. (3) Hydraulic shift control system: The hydraulic control system consists of a valve plate assembly consisting of a number of control valves and a hydraulic line. The valve plate assembly is usually installed in the oil pan below the gear transmission. Accept the throttle opening and speed signal, the use of hydraulic automatic control principle, to achieve automatic shift

(4) Electronic control system: With the development of automatic transmission, the current use of electro-hydraulic automatic transmission more and more electro-hydraulic control system in addition to the valve plate and hydraulic lines, including computers, sensors, actuators and Control circuit and so on. The sensor will be the engine and the car driving parameters into electrical signals, and then sent to the automatic transmission of the computer, the computer receives these signals according to the established shift rules to achieve automatic shift. 


\subsection{Automotive electronic control automatic transmission works}

\section{Hydraulic torque converter working principle}

Hydraulic torque converter to convert energy, transmission power principle and the liquid coupling is basically the same, the fundamental difference is that the hydraulic torque converter to increase a work wheel-guide wheel. When the engine is running, the pump wheel rotates together, and the working fluid in the pump wheel is driven by the centrifugal force of the pump wheel and flowed along the turbine blade to the guide wheel, rotate the inner edge of the blade to form a circulating stream. As a result of the more fixed guide wheel, in the process of liquid circulation, the fixed guide wheel to the turbine a reaction torque, so that the turbine output torque is different from the pump wheel input torque.

The principle of the torque converter is described by the expansion of the working torque of the torque converter. The turbine wheel $\mathrm{B}$, the turbine $\mathrm{W}$ and the guide wheel $\mathrm{D}$ become three annular planes arranged in a straight line along the straightening line, as shown in Figures 3, so that the working wheels Leaves clearly show up.

\section{Planetary gears working principle}

Planetary gears are composed of sun wheels and several planetary wheels that are distributed around the sun wheel and gears that mesh with the planetary wheels and several planets are simultaneously mounted on a common planet carrier. Schematic diagram of a single planetary row.

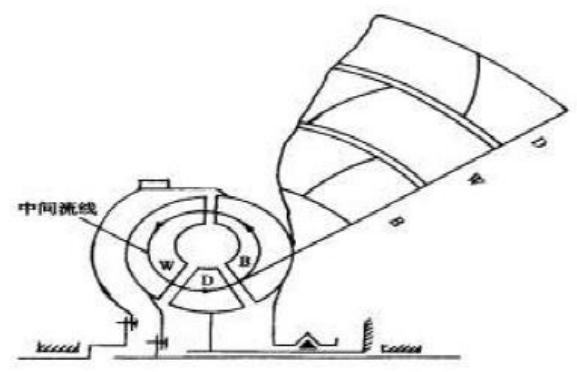

Figure 3. Hydraulic torque converter working wheel development diagram

In an automatic transmission, the number of planets depends on the number of automatic transmission gear. Automatic transmissions rely on different combinations of components in these planets to achieve different gear outputs.

As seen from Figure 4, the sun wheel and the planetary wheel are external meshing, so the direction of rotation of the two wheels is always the opposite. And the meshing wheel and the ring gear meshing, the planetary wheel and the ring gear rotation direction are the same. Through the clutch, brake and one-way clutch to the different components of the connection, lock the combination, you can get the automatic transmission of different transmission ratio.
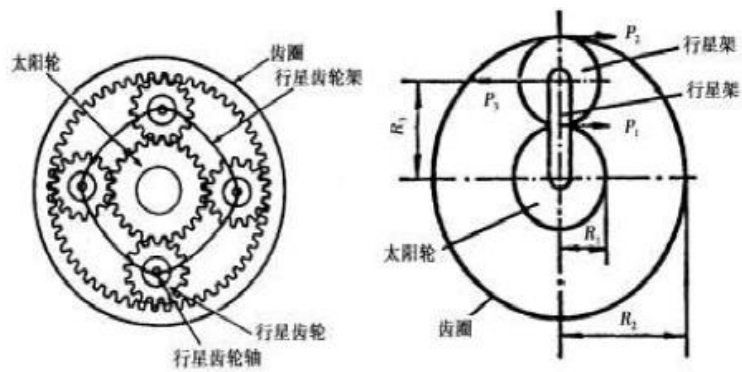

Figure 4. Schematic diagram of single-stage planetary row structure

\section{Hydraulic control shift system}

Automatic transmission is able to achieve automatic shift because the driver in the position of the driver down the throttle or engine intake manifold vacuum and the speed of the car can command the automatic shift system work, automatic control system in the control valve. The different working conditions will control the separation and coupling of the clutch in the variable speed gear mechanism and the braking and release of the brake and change the power transmission path of the transmission mechanism to realize the transmission of the transmission gear. 
Hydraulic control automatic transmission according to the car's driving speed and throttle opening changes, automatically change the gear. The shift control mode is to mechanically convert the throttle opening signal and the vehicle speed into the control oil pressure, and apply the oil pressure to the upper and lower ends of the shift valve respectively to control the position of the shift valve, so as to change the oil path of the shift actuator (clutch and brake). In this way, the working hydraulic oil enters the corresponding actuating element, causes the clutch to be engaged or separated, the brake is braked or released, and the planetary gear transmission upshifts or downshifts are controlled to achieve automatic speed change. The process is shown in Figure 5.

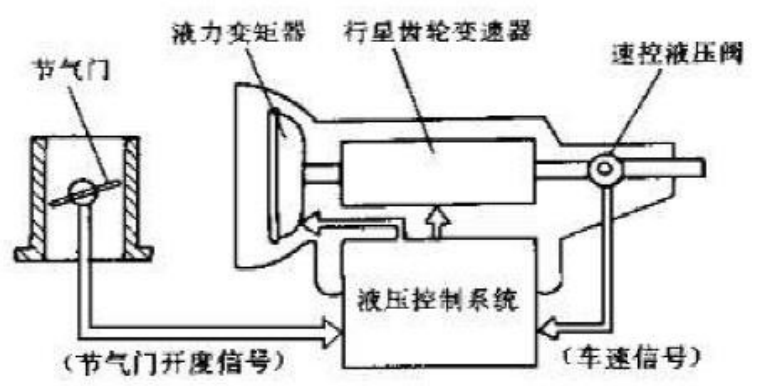

Figure 5. Hydraulic control automatic transmission work process diagram

\section{Electronic control system}

The sensor provides the vehicle speed, throttle position opening and other signals. The electronic control unit determines the shift or locks time as described above, and then outputs the corresponding control signal to the solenoid valve. Solenoid valve can be controlled by the hydraulic work to complete the electronic control unit issued by the shift, lock the command. The electronic control system also has a self-diagnostic device and has the ability to continue the vehicle in the event of a failure.

\section{Upshift is not the cause of failure}

\subsection{Initial inspection of engine and automatic transmission.}

\section{Engine Check:}

(1) Idling normal, the ignition is good; the speed is not a lack of fire, off the fire, cross the ignition.

(2) Single cylinder power is good-cylinder pressure is greater than $800 \mathrm{kPa}$; intake pipe vacuum $\Delta \mathrm{px}$ greater than $60 \mathrm{kPa}$; single cylinder power off, breaking oil speed drop value greater than $100 \mathrm{r} / \mathrm{min}$ or $\Delta \mathrm{px}$ drop value is greater than $5 \mathrm{kPa}$.

(3) The water temperature is normal, the discharge value is normal, no abnormal symptoms, ECU fault light does not shine (Figure 6).

Automatic transmission check:

(1) Drive system and roadway mechanism, operating in good condition, four rounds of flexible rotation, tire size and pressure normal, no brake block phenomenon.

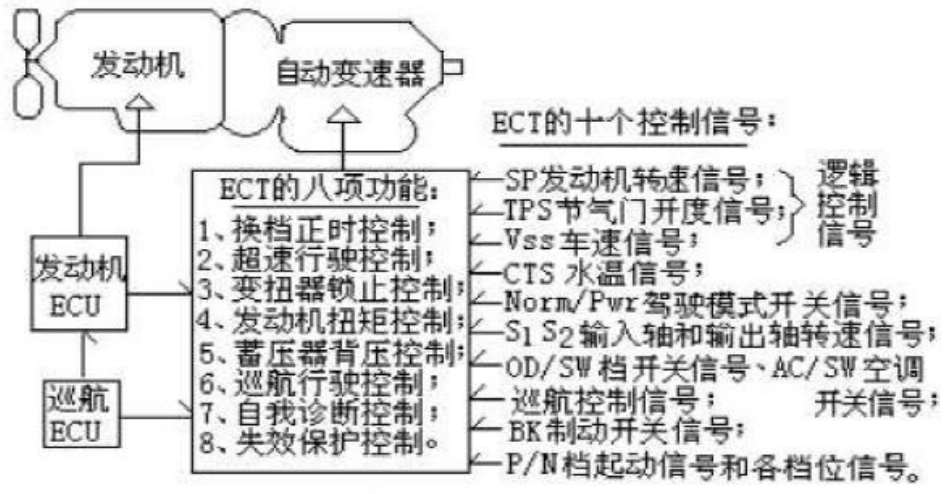

Figure 6. 
(2) What is the performance status of the automatic transmission? Are there abnormalities and high temperatures? Such as AT fault lights have been lit, can directly read the code, transferred to the AT key test.

(3) Automatic transmission fault code detection and elimination - contemporary passenger vehicle fault code check connector, all using a unifi ed OBD-II type. Can be used to take the code or code to take code method. AT fault code is about 20 or so, covering a variety of electrical components and related failures, e.g:

A, Toyota, General Motors - Fault code for wires crossing 6 \# -5 \#, IG/SW-ON, flash ECU and ECT.

B, Honda cars - with wire cross 9 \# -4 \#, IG/SW-ON, fl ash the system fault code.

C, Mitsubishi car - with LED lights cross +6 \# - 4 \#, IG/SW-ON, LED lights fl ash ECT fault code.

\subsection{Basic inspection: the automatic transmission of good or bad test.}

\section{Level test:}

The car in the level of the ground, the engine in the heat from the idle state, the stalls converted 1 or 2 times, and then back to the P file, with the dipstick check the level of liquid level should be high oil level and low oil level mark between as well. When the liquid level is too low, the control oil pressure is reduced, due to lack of oil, shift shock, friction plate slip, the relevant components to accelerate wear; liquid level is too high, due to poor valve body displacement, shift is not sensitive.

\section{Quality test:}

(1) The quality of the oil to the color, impurities, impurities, abrasive, viscosity, purity, oil temperature, gum, odor, and milk foam as the standard test.

(2) ATF oil color is scarlet or pale yellow, impurities and abrasive mixed into a dark brown. High temperature oxidation and aging deterioration, easy to produce gum and odor, viscosity deterioration, affecting the transmission of power and stability of the control of oil pressure, and the slide valve cannot be flexible to move. When the oil has milky foam, mixed with oil and water, mostly for the radiator in the cooler caused by leakage, or wading caused by water, should be timely oil change.

(3) The replacement cycle of oil is $40,000 \mathrm{Km}$ and the practice of "no change" should be stopped. Must use the specifi ed ATF oil, or use Dexron-II type or type III general purpose oil. Most of the torque converter without oil plug, there are nearly $1 / 3$ of the oil cannot be released, the dirty or water AT should be changed for many times to clean or remove the cleaning.

\section{Throttle valve full degree of inspection:}

Some electronic control of the hydraulic AT, also equipped with throttle valve, the purpose is only to make the shift control hydraulic follow-up changes, to achieve high torque, high oil pressure control. Many cars are equipped with the main oil circuit regulator PWM, that is not installed this valve, eliminating the need for cable agencies. Throttle valve with cable and accelerator pedal soft connection, loose cable can easily change, can be used to adjust the nut on the catheter, the cable is equipped with "full mark" to monitor. When the accelerator pedal stepped on the end, this mark should be about $1 \mathrm{~mm}$ from the cable guide mouth as well. This is the "full control" normal state, that is, control the oil pressure is proportional to the follow-up changes in the state.

\section{Gear switch check:}

Shift handle cable tension, can be adjusted, it affects the gear slide switch contacts in place. If the ECT loses the gear signal, the AT is no longer automatically shifted and can only be driven in 1 or $\mathrm{R}$ range.

(A) P / N start switch is good or bad check - handle in the P/N file, the starter should be able to turn on the start, the other gear should not be turned on to ensure safety.

(B) Handle In any gear, the indicator light on the instrument panel should be synchronized.

(C) When the vehicle with the overdrive switch - OD/SW-ON/OFF, the indicator light should be displayed simultaneously. 


\section{3. upshift and the slippage}

Electronic control automatic transmission caused by the lifting speed is not the main reason for the slippage when the shift, upshift slow, no over speed, and so on.

\section{Slip when the slip causes:}

Hydraulic oil is too low; clutch or brake wear serious; oil pump wear serious, the main oil leakage caused by the main oil pressure is low; one-way clutch slip; clutch or brake seal damage caused by oil; shock absorber piston Damage to the seal causes oil spills.

\section{Upshift slow cause of failure:}

Valve stem or throttle position sensor adjustment improper; governor failure; output shaft governor inlet and outlet of the seal ring damage; vacuum throttle valve putter improper adjustment; vacuum throttle valve vacuum hose or vacuum film. The main oil pressure or throttle oil pressure is too high; forced downshift switch short circuit; sensor failure.

\section{No overspeed fault Cause:}

Overspeed switch failure; overspeed solenoid valve failure; overspeed brake skid; speeding planetary row of direct clutch or direct one-way clutch failure; gear switch failure; hydraulic oil temperature sensor failure; throttle position sensor failure; Stall valve stall.

Third, the automatic control of automotive automatic transmission is not speed up the diagnosis of exclusion

\subsection{Electronic control automatic transmission maintenance tools:}

Maintenance of auto automatic transmission using a lot of tools, can be summarized into the following categories:

1. Commonly used tools: Allen wrench, hexagonal wrench, sleeve and torque wrench, pliers, gun son, file Knife, tap and die, etc.

2. Special tools: bearings, bushings and special gear, positioning ring clamp, and so on.

3. Power tools: pneumatic or electric wrench, ratchet and so on.

4. Lifting tools: jack, safety bracket, hydraulic or electric lift and so on.

5. Measurement tools: diameter micrometer, diameter micrometer, dial indicator, feeler and so on.

6. Detection equipment: multimeter, oscilloscope, monitor and fault detector, and so on.

\subsection{Electronic control automatic transmission fault diagnosis and removal procedures}

Fault diagnosis and testing procedures:

preliminary inspection $\rightarrow$ fault code check $\rightarrow$ manual shift test $\rightarrow$ mechanical system test $\rightarrow$ hydraulic system test

$\rightarrow$ electronic control system test $\rightarrow$ check the common faults and causes analysis and troubleshooting methods.

According to the fault phenomenon analysis, confirm the fault phenomenon.

(1) If the electronic control automatic transmission, and fault indicator light, the first self-diagnosis to read the fault code, excluding the fault code represented by the fault.

(2) For automatic transmission and engine routine inspection, the main items to be checked are:

A. The oil level and oil quality.

B. The accelerator pedal cable and throttle position sensor.

C. The selector handle linkage lever system.

D. The neutral start switch and gear switch.

E. The engine idling speed.

F. The tire pressure and other relevant parts of the drive train.

(3) Stall test, check the engine and automatic transmission internal mechanical and technical status.

(4) Manual shift test; to determine whether the fault is in the electronic control part or inside the automatic transmission.

(5) Time delay test, check the daily transmission clutch, brake wear.

(6) Electronic control system self-diagnosis and component and line detection. 
(7) Hydraulic test, check the pump, regulator, governor oil pressure and oil pressure.

(8) Carry out road tests, check the automatic shift point, with or without abnormal noise, vibration, slippery and the engine braking effect.

(9) Synthesize the test results, analyze and judge the cause and location of the fault.

\subsection{Electronic control automatic transmission upshift is not speed diagnosis method}

\section{Slip when troubleshooting}

(1) Fault phenomenon

Start step on the speed pedal, the engine speed rise quickly but slow speed; uphill when the power, the engine speed rise is high.

(2) Cause of the malfunction

Hydraulic oil is too low; clutch or brake wear serious; oil pump wear serious, the main oil leakage caused by the main oil pressure is low; one-way clutch slip; clutch or brake seal damage caused by oil; shock absorber piston damage to the seal causes oil spills.

(3) Exclusion method

Check the hydraulic oil surface height and oil quality; if the hydraulic oil discoloration or burning smell, indicating the clutch or brake friction plate burned, should be removed automatic transmission.

(4) Road test

If all files are skid, the reason out in the forward clutch. If the optional handle in the D position of the two slips, and in the S position of the second gear does not slip, indicating that the two-way one-way clutch slip. If both in the D-bit, S-bit when the two files are skipped, then low and reverse gear brake slippage. If the slippage in the third gear, because the reverse gear and high-grade clutch failure. If the overspeed slips, the overspeed brake failure. If the reverse gear and highgrade skid, the reverse gear and high-grade clutch failure. If the reverse gear and 1 file slip, then low and reverse gear brake slippage.

In the forward or reverse gear are slippery, indicating that the main oil pressure is low. At this point should be pump and valve body maintenance. If the main oil pressure is normal, the reason may be clutch or brake friction plate wear or excessive charring, replace the friction plate can be.

\section{Upshift slow cause of failure:}

(1) Fault phenomenon

When the car is running, the upshift speed is higher and the engine speed is also high. The accelerator pedal must be released before lifting the gearbox to make the automatic transmission high.

(2) Cause of the malfunction

Throttle valve or throttle position sensor adjustment improper; governor failure; output shaft governor inlet and outlet of the seal ring damage; vacuum throttle valve putter improper adjustment; vacuum throttle valve vacuum hose or vacuum diaphragm leakage; main oil pressure or throttle oil pressure is too high; forced downshift switch short circuit; sensor failure.

(3) Exclusion method

Electronically controlled automatic transmission should be fault diagnosis. Check and adjust the throttle cable or throttle position sensor, measure the throttle position sensor resistance; if not meet the standard, replace these parts. Vacuum throttle valve with automatic transmission, should check whether the vacuum hose leak. Check whether the forced downshift switch is shorted.

Measurement of the main oil pressure, if the oil pressure is too high, should be throttle line or throttle position sensor to be adjusted. The use of vacuum throttle valve automatic transmission, the application of reducing the throttle valve putter length method to adjust. If the above adjustment is invalid, should check the hydraulic valve or throttle valve. 
Measure the governor oil pressure, the governor oil pressure should increase with the speed of the increase. The different speed measured under the governor oil pressure and the specified value, if the oil is too low, indicating the governor failure or governor oil circuit leakage. At this point should be demolished automatic transmission, check the governor fixing screw is loose, governor oil seal ring is damaged, the spool is stuck or excessive wear.

If the governor oil pressure is normal, the reason for the slow downshift may be that the shift valve is working poorly. Disassemble the valve body and replace it if necessary.

\section{No overspeed fault Cause:}

(1) Fault phenomenon

Car driving, cannot be extended from the 3 gear over speed; speed has reached the range of work over the use of loose speed pedal for a few seconds and then depress the accelerator pedal method, automatic transmission cannot be promoted to overdue gear.

(2) Cause of the malfunction

Overspeed switch failure; overspeed solenoid valve failure; overspeed brake skid; speeding planetary row of direct clutch or direct one-way clutch failure; gear switch failure; hydraulic oil temperature sensor failure; throttle position sensor failure; Stall valve stall.

(3) Exclusion method

Automatic control of the electronic control system should be fault diagnosis, check whether the fault code output. Check the hydraulic oil temperature sensor resistance value; check the output signal of the gear switch and throttle position sensor. Gear switch, the signal should be consistent with the position of the selector handle; throttle position sensor output voltage should be proportional to the opening of the throttle.

Check the overdrive switch. In the on position, the overdrive switch contact should be disconnected, the indicator light does not light; in the off position, the overdrive switch contact should be closed, the indicator light should be bright. Otherwise check the overdrive circuit or replace the overdrive switch.

Check the operation of the overdrive solenoid valve. Turn on the ignition switch, do not start the engine, press the o/d switch, the overspeed solenoid valve should have the joint sound. If there is no engagement sound, check the control circuit or replace the solenoid valve.

Lift the vehicle with a lift, so that the four wheels are vacant. Start the engine, so that the automatic transmission in the work, check in the no-load state automatic transmission upshift situation. If you can ascend the overdrive, and the speed is normal, indicating that the control system is working properly. If you cannot ascend the overdrive because the overspeed brake slips, so in the case of a load cannot be promoted to overdrive. If you can ascend the overdrive, and the upshift speed is not high, the engine speed down, indicating that the speed of the planets in the direct clutch or direct one-way clutch failure. If the load cannot be elevated in the case of overload, indicating the control system is faulty, should check the valve body, check the $3 \sim 4$ shift valve.

\section{Conclusion}

Automatic transmission is a set of machines, electricity, liquid in one of the high-tech products, the structure of the principle, the detection process are extremely complex, which requires us not only to have the spirit of tireless study, but also we need in the actual work, continue to accumulate this experience, the combination of theory and practice, the only way we can in the future practical work in handy, learn by analogy. We hope this paper can be based on their knowledge on the basis of sublimation, to the reader to revelation, and we encourage each other.

\section{References}

1. Zhou Fulin, Automotive Chassis Construction and Maintenance, People's Communications Press, 2005.

2. Wu Yuji, automobile automatic transmission construction and maintenance, People's Communications Press, 2002.

3. Tang Ming, automatic transmission fault diagnosis manual, Liaoning Science and Technology Press, 2001.

4. Tu satellite, car chassis construction and maintenance, People's Communications Press, 2001.

5. Yang Hongjin, automatic transmission, machinery industry press, 2010 